\title{
The Girl With Rapunzel Syndrome
}

\author{
Norly Sa, Nor Saadah Ia, Ros'aini Pa \\ ${ }^{a}$ Department of Surgery, Hospital Sultanah Fatimah, Muar, Johor, Malaysia
}

\begin{abstract}
Rapunzel syndrome is a syndrome whereby a gastric trichobezoar (hair ball) extends through the pylorus, in the form of a long tail, to cause gastric outlet obstruction. It was first described by Vaughan et al. in 1968. The syndrome is mostly seen in young females with psychiatric illness. Presentations can be non-specific especially in the early stages. If left untreated it may leads to severe complications, which may include gastric ulceration, intestinal obstruction, perforated viscus and obstructive jaundice. Treatment is essentially surgical and psychiatric consultation is necessary to prevent relapses. We present the case of a 26 -year-old mentally subnormal lady with gastric trichobezoar and provide a review of the literature.
\end{abstract}

KEYWORDS: Rapunzel syndrome, trichobezoar, gastric outlet obstruction

\section{INTRODUCTION}

Rapunzel syndrome is a syndrome whereby a gastric trichobezoar (hair ball) extends through the pylorus, in the form of a long tail, to cause gastric outlet obstruction. It was first described by Vaughan et al. in 1968.1 It is named after Rapunzel, the heroine of a German fairy tale by the Grimm brothers. This condition is almost always associated with trichotillomania (hair pulling) and trichophagia (hair ingestion).

The hair is collected over a period of time in the stomach. As hair is indigestible, it became tangled with food and mucus causing the formation of trichobezoar. The hair ball is mostly confined to the stomach but it may extend into the duodenum, jejunum, ileum or even colon. Some part of the trichobezoar may become dislodged and cause small bowel obstruction. Trichobezoar is typically seen in young female patient with psychiatric illness. Presentations can be nonspecific especially in the early stages. They may have early satiety, abdominal bloatedness, vomiting, epigastric pain and weight loss. If left untreated it may lead to severe complications for example gastric ulceration, intestinal obstruction, perforated viscus and obstructive jaundice.

\author{
Corresponding aAuthor: \\ Norly Salleh \\ Department of Surgery, \\ Hospital Pakar Sultanah Fatimah, Jalan Salleh, \\ 84000 Muar, Johor \\ Malaysia. \\ Telephone: 00-60-12-6911644 \\ Fax: 00-60-6-9526003 \\ Email: norlysalleh@gmail.com
}

\section{CASE REPORT}

Our patient is a 22-year-old Malay girl, who is mentally subnormal, as well as deaf and mute. She has an idiopathic end stage renal failure on regular dialysis. She presented with vomiting associated with an abdominal mass. On examination she looked cachexic and her weight was only $26 \mathrm{~kg}$. Her vital signs were stable. Per abdomen examination revealed an epigastric mass estimated about $10 \times 10 \mathrm{~cm}$.

Ultrasound examination was non-diagnostic. A clinical diagnosis of gastric cancer was given and an oesophagoduodenoscopy examination was arranged. During the procedure it was noted that her entire stomach was filled with hair ball and it was causing a partial gastric outlet obstruction.

Endoscopic removal was attempted but was unsuccessful. She was then subjected to a laparotomy and the hair ball, weighing $645 \mathrm{~g}$, was removed from her stomach via a gastrotomy wound (Figure 1 and 2). The stomach was primarily repaired and the abdomen was closed with a drainage. She was discharged well less than one week later with no complications noted on follow up appointment. 


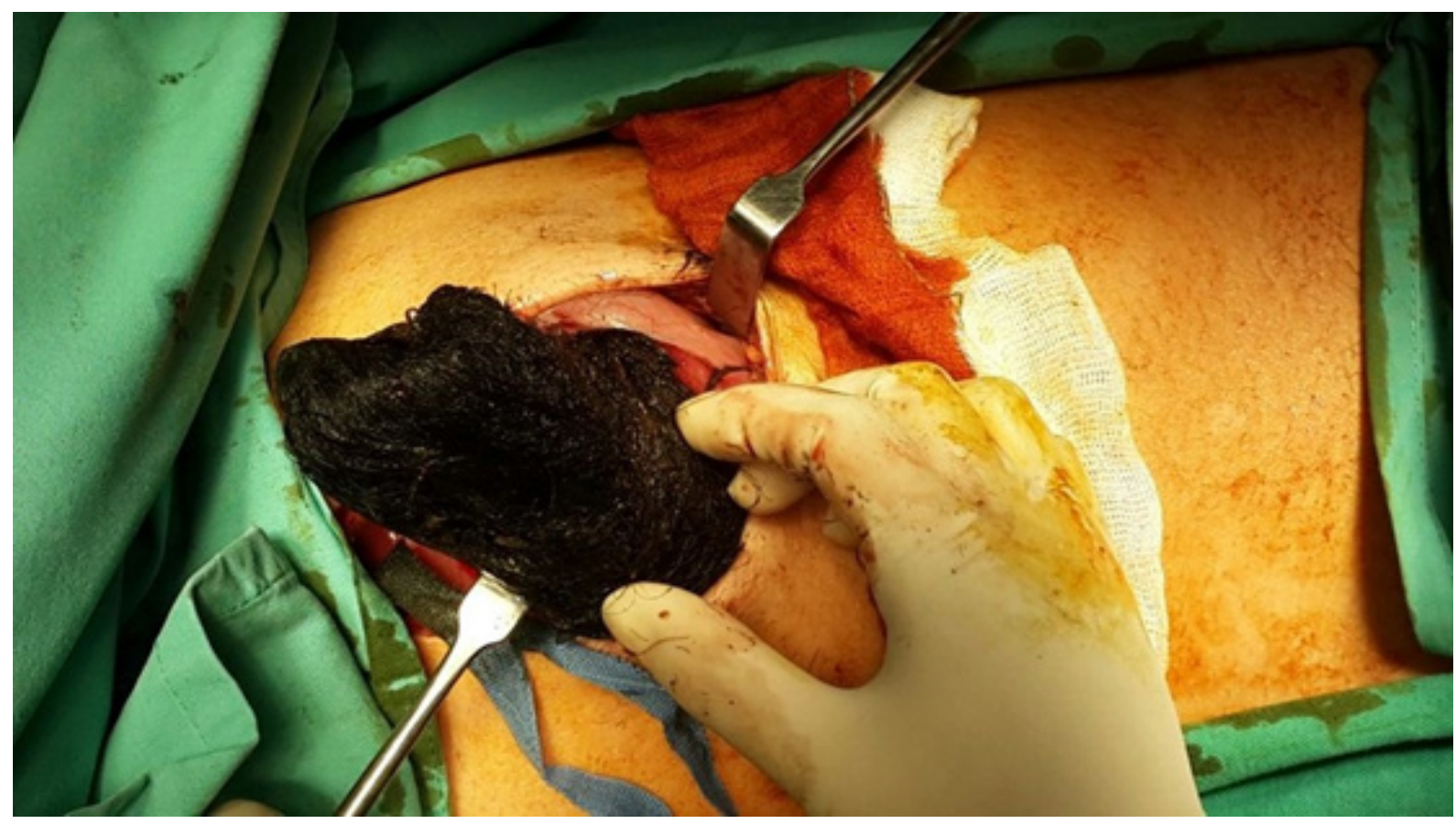

Figure 1. Trichobezaor extracted from the stomach following gastrotomy

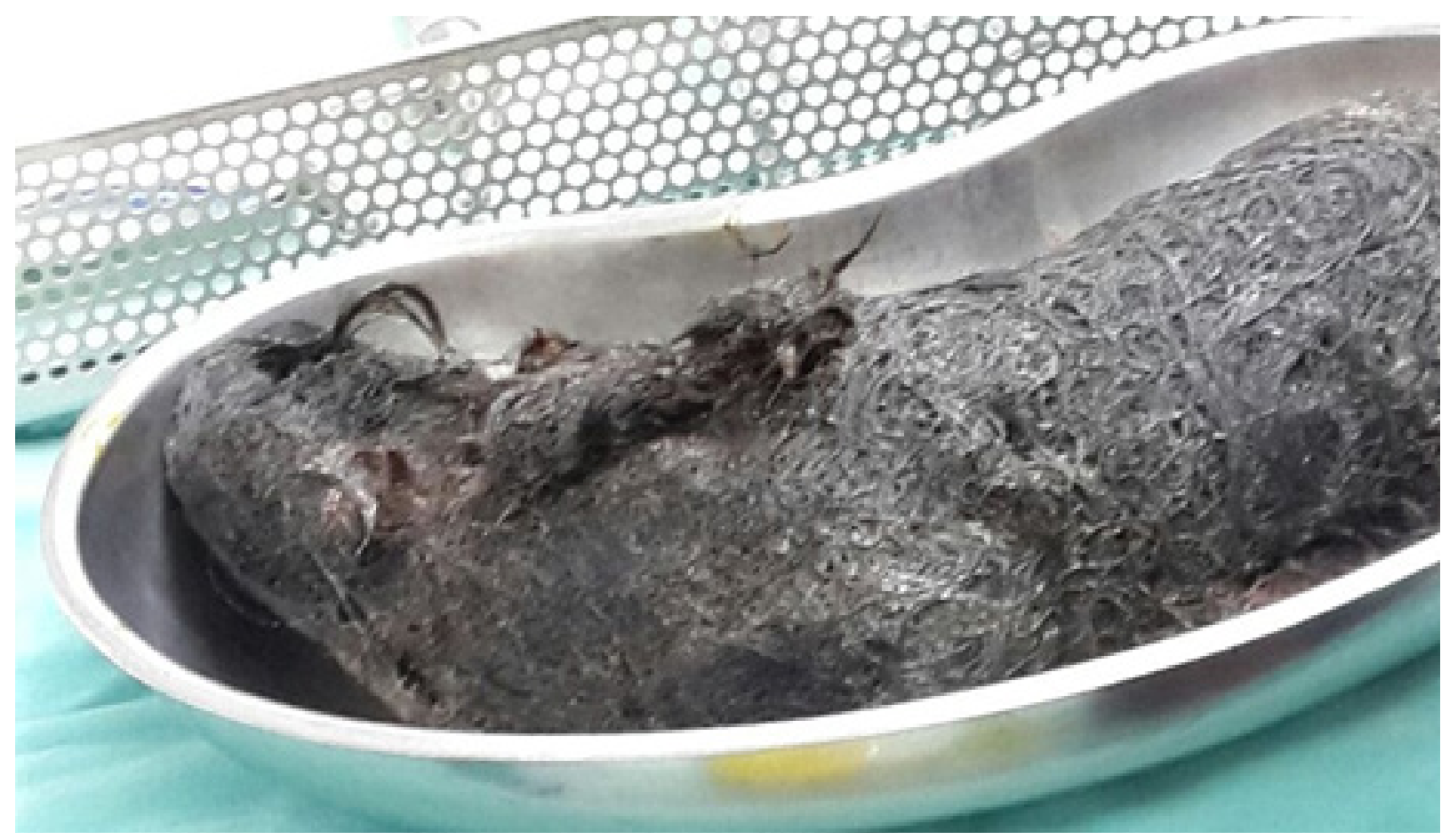

Figure 2.: Full extend of the hair ball occupying the whole kidney dish

\section{DISCUSSION}

Rapunzel syndrome is a rare condition occurring mostly in female patients. Clinical presentation of these patients may be confusing as they are usually not forthcoming with a history of trichophagia. In our case the patient is mentally challenge who is also deaf and mute. Therefore history taking was a bit of a challenge. As she had a mass in the epigastric region, it was interpreted as suspected for gastric malignancy.
Diagnosis is usually established via endoscopy or computed tomography scan. Ultrasonograpy is not the diagnostic modality of choice as the sonographic features are not pathognomonic. ${ }^{2}$ Endoscopy has the added advantage of distinguishing between phytobezoars from trichobezoars because this can make a difference in terms of management. Phytobezoars may be soften by enzymatic dissolution and many 
authors have even used Coca-Cola to dissolve them. ${ }^{3,4}$ Removal of trichobezoars, however, almost always requires surgical treatment.

In the management of trichobezoars, endoscopy should be used as a diagnostic tool and not for therapeutic purpose unless for a very small trichobezoar. Laparoscopic removal of trichobezoars is also possible 5,6 but it may be associated with spillage of hair or gastric juice during retrieval which could lead to intra-abdominal and wound infection. Conventional laparotomy is still the treatment of choice. ${ }^{7,8}$ Through laparotomy exploration of the rest of the bowel to look for detached bezoars is possible and can be easily done.

Gorter et al. in $2010^{8}$ did a review of management of trichoebezoars and found that out of 40 cases of endoscopic removal of trichobezoar only 2 were successful (5\%). Laparoscopic removal showed 75\% success rate and laparotomy removal showed 99\% success rate. However laparotomy removal was associated with $12 \%$ complications.

As the majority of these patients are suffering from a psychiatric illness, the need for psychiatric evaluation and follow up is important. The underlying illness need to be treated i.e. trichotillomania and tricophagia. This is essential to diminish the frequency of recurrence.

\section{CONCLUSION}

In conclusion, trichobezoar should be considered as a differential diagnosis in young females who present with non-specific symptoms such as epigastric pain, vomiting and epigastric mass.

\section{REFERENCES}

1. Vaughan ED Jr, Sawyers JL \& Scott HW Jr. The Rapunzel syndrome. An unusual complication of intestinal bezoar. Surgery 1968; 63:339-43.

2. O'Sullivan MJ, McGreal G, Walsh JG \& Redmond HP. Trichobezoar. J R Soc Med 2001; 94:68-70.

3. Kramer SJ \& Pochapin MB. Gastric phytobezoar dissolution with ingestion of diet coke and cellulase. Gasteroenterol Hepatol 2012; 8:770-2.

4. Ladas SD, Kamberoglou D, Karamanolis G, Vlachogiannakos J \& Zouboulis-Vafiadis I. Systematic review: coca-cola can effectively dissolve gastric phytobezoars as a first-line treatment. Aliment Pharmacol Ther 2013; 37:16973.

5. Nirasawa $\mathrm{Y}$, Mori T, Ito $\mathrm{Y}$, Tanaka $\mathrm{H}$, Seki $\mathrm{N} \&$ Atomi Y. Laparoscopic removal of a large gastric trichobezoar. J Pediatr Surg 1998; 33:663-5.

6. Javed A, Agarwal AK. A modified minimally invasive technique for the surgical management of large trichobezoars. J Min Access Surg 2013; 9:42-4.
7. De Backer A, Van Nooten V \& Vandenplas Y. Huge gastric trichobezoar in a 10 year-old girl: case

report with emphasis on endoscopy in diagnosis and therapy. J Pediatr Gastroenterol Nutr 1999; 28:513-5.

8. Gorter RR, Kneepkens CM, Mattens EC, Aronson DC \& Heij HA. Management of trichobezoar: case report and literature review. Pediatr Surg Int 2010; 26:457-63. 